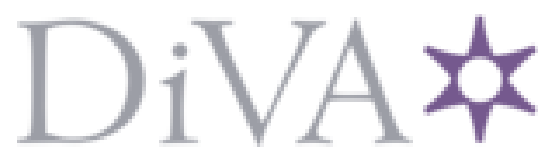

http://www.diva-portal.org

This is the published version of a paper presented at International Conference on Information Society 2010.

Citation for the original published paper:

Kajtazi, M. (2010)

Information Asymmetry in the Digital Economy.

In: Charles A. Shoniregun (ed.), Proceedings of the IEEE International Conference on Information Society (i-Society 2010) (pp. 148-155). London, UK: IEEE UK/RI Computer Chapter

N.B. When citing this work, cite the original published paper.

Permanent link to this version:

http://urn.kb.se/resolve?urn=urn:nbn:se:Inu:diva-7323 


\title{
Information Asymmetry in the Digital Economy
}

\author{
Miranda Kajtazi \\ School of Computer Science, Physics and Mathematics \\ Linnaeus University, Växjö, Sweden \\ miranda.kajtazi@lnu.se
}

\begin{abstract}
Information asymmetry is a problem that prevents communication processes to be effective in the digital economy. In this paper, we propose a model for understanding information asymmetry. Our analyses are conducted using the newspaper industry, the healthcare sector, and the stock exchange market. These analyses are examined using theories of communication processes in which two or more actors are necessary to engage in activities of information exchange. The study of these three examples resulted in the identification of four information exchange patterns: influenced, intentional, hindered, and unawares. Furthermore, we discuss implications of the model for information exchange in practice. The paper concludes by challenging sustainability in the digital economy, which remains problematic and difficult to achieve.
\end{abstract}

\section{Introduction}

The growing global structures of economies and societies have had a major impact on information systems (IS) [1]. They have influenced new trends of global communication throughout the last decades. Such trends continue, through the introduction of entirely new forms of technologies that have fundamentally changed information flows between economic and social global structures [2]. This signals the transformation from the industrial revolution to the networked society and economy [3]. Whilst the latter continuously gives rise to new models and patterns of information flow, many models' developments are still impeded. This challenges the combination of information systems' capabilities and the economy, interpreted as the digital economy, which influences profoundly our global society and transforms it into an electronic society or eSociety [2,4].

The objective of this paper is to develop a model that demonstrates how information asymmetry leads communication processes towards uncertainty. We describe information asymmetry as an imbalanced information exchange between actors that share information with others $[5,6]$. The focus of this paper is on information asymmetry in organisations, such as the newspaper industry, the health care sector, and the stock exchange market. Individuals, who contribute their skills to these organisations, are very likely to possess important information that could be helpful to others [7]. In general, their information can be accessed via various information and communication technologies (ICTs), including email, voice mail, and other related ICTs. This is known as the digital economy, which brings new activities and new forms of connectivity, through the use of the Internet [2].

The paper is structured as follows. We first present the motivation behind these efforts. Then we introduce the two new dimensions that of the digital economy and sustainability in line with IS. Second, we present the concept of information asymmetry, by setting out its meaning in two ways: a. understanding information exchange; and, b. understanding its activities through the use of three examples. Furthermore, we introduce the results of these analyses, by first presenting four identified patterns, which are derived from the three examples. This is followed by the introduction of the model of information asymmetry. This model highlights the way information asymmetry affects information flow in communication processes. Finally, we discuss the implications of this model for future configurations of current information and communication technologies.

\section{Motivation}

While many understand the basic changes in the networked society and economy, we are yet unclear about the digital economy; about how we characterise information exchange. There are several interferences that paralyse profitable communication processes. Hence, the key question of investigation in this paper is:

Why do many organisational structures appear to be irreversible and static in relation to the digital economy, such as types of working practices and cultural behaviours, yet the digital economy imposes 
some critical changes on how we produce and spread information?

To address the aforementioned question, our approach focuses on scrutinising the role of information asymmetry in the three sectors introduced earlier. These three examples are regarded as economic arenas that are heavily dependent on digital information. We also intend to illustrate how and if the digital economy, in relation to these examples, resonates sustainability. This is achieved by referring to the role of individuals who often struggle to find the information they need to make good decisions.

This motivates analysis of the rise of new models and patterns of information flow, many considered unsustainable [8]. The intention is to theorise about how the digital economy fosters innovative trends in the global economy and in society. Yet, at the same time, it increases the risk of de-systematising information flow between the economic and social global structures [8].

In the following section, we introduce the meaning of digital economy and sustainability in the networked economy and society and we group them into two new inter-related dimensions of IS.

\section{Dimensions of digital economy and sustainability in information systems}

Digital economy, as described by Tapscott in 1995 , is about reducing the old traditions of physicalbased interactions, into information transfer at the speed of light, through new information forms that have become digital [9]. As Internet advances continue [10], the digital economy has also advanced. This notion is defined as the power of communication and information processing [11]. More precisely, digital economy is the new economy represented by the inclusion of technology and digital information.

Recently, it has been argued that the digital economy represents the digitisation of information combined with the Internet [10]. This involves dynamic activities and gives rise to new ways of communication and innovative economic transactions $[2,4]$.

This clearly denotes the experience of transformations and progression in our global society in the last decades. It also indicates potential sustainability, through the balance of many economic, social, and environmental activities [12]. On the one hand, this suggests that the digital economy expands the horizon of new possibilities for the digitisation of information, with increased productivity, a well-informed society, and a sustainable environment. On the other hand, we consider that the digital economy implies the need for enhanced innovations, as it is not sustainable in relation to the many ways of how information exchange permits interaction between different actors.

Therefore, global developments and changes in the new digital economy and eSociety challenge the need for sustainability to be aligned with IS [1]. Thus, the notion of sustainability is broadly defined as:

"an international interdisciplinary effort to blend environmental and economic goals" [13], which "requires different meanings, in different contexts, and at different times" [12].

Generally, the concept of sustainability has been used widely in different fields. It has been defined within boundaries of certain aspects, such as corporate management, energy and environmental factors, sustainable industry, and other similar examples [1, 12, 14]. More broadly, it has been discussed within the fields of economy, ecology, and society [1], known as the three main pillars of sustainability.

In this context, sustainability is more than merely protecting the environment and being energy efficient. Indeed, sustainability is about the integrated triplet of economy, ecology, and society, and transforms it into a system that is indefinitely maintained in a healthy state [14]. In this paper, sustainability is contextualised in relation to the IS discipline, which we adapt from [1], as:

“... a cross-sectional objective that applies to all IS resources, to improve their accumulation, generation, deployment and securing...".

Until recently, both concepts (digital economy and sustainability) have started to be characterised as new inter-related dimensions in the area of IS. Even if many concerning issues of these dimensions in IS have already been introduced, surprisingly, they have not been thoroughly investigated in relation to information management and digital information [1].

Consider the following case: many organisational information transactions are accomplished through ICTs replacing older paper-based methods. However, several impediments have also emerged: the creation of unnecessary extra work through information inefficiencies, triggered by the digital economy in practice, which have been interfered by information asymmetry.

Such impediments present underdeveloped contributions in offsetting the digital economy involved with sustainability in IS. Accordingly, the next section introduces the notion of information asymmetry, followed by three examples based within the economic arena. 


\section{Some examples of information asymmetry}

One of the most interesting and powerful tools in economics is the theory of information asymmetry. This theory provides insight into economic transactions, communication processes, or production processes. The analyses for this theory undertaken thus far, suggest that information asymmetry connotes the presence of imbalance in the flow of information in any economic transaction [16, 17]. For example, when we, as consumers, buy certain types of products (this can be best linked to when consumers buy IT equipment), we search the Internet to find the best possible information, which ranks the desired product. We usually perform a search activity, hoping that it will provide us with useful information. In such cases, product reviews are particularly helpful. However, in many cases, they reflect a total imbalance of information, and the consumer suffers from the experience of imperfect information. This example is regarded as information asymmetry, which creates a state of confusion in our own decision-making activities [8]. Moreover, it also negatively affects the way we estimate productivity and economic growth [11].

Previous analyses and examples of information asymmetry have been discussed in terms of quality and uncertainty, mostly in relation to two actors that are in an economic transaction [6, 15, 16, 17]. Akerlof's paper in 1970 The Market for Lemons: Quality Uncertainty and the Market Mechanism, awarded him the Nobel Prize in Economics, in which he discusses information asymmetry that occurs between two actors: a seller and a buyer, where the seller knows more about a product than the buyer.

Akerlof's examples were related to the automobile market. He depicted the automobile market as a model of information asymmetry, by taking, as an example, the seller-buyer relationship, in relation to buying new and/or old cars.

His analyses assumed that any complete and available information for a car is one-sided, suggesting that such information can only be available to the seller. This emphasises Akerlof's interpretation that a buyer can buy a good car yet there is a high probability that the buyer would not be able to identify that the car was a "lemon". Akerlof elaborated:

"After owning a specific car, however, for a length of time, the car owner can form a good idea of the quality of this machine; i.e., the owner assigns a new probability to the event that his car is a lemon. This estimate is more accurate than the original

\footnotetext{
${ }^{1}$ An American idiom indicating that a used car can be a bad car, and also a new car can be a bad car.
}

estimate. An asymmetry in available information has developed: for the sellers now have more knowledge about the quality of a car than the buyers" [6].

Finally, the theory of information asymmetry is a framework that allows us to examine other interesting aspects; one is the evidence regarding how imbalanced patterns of information flows develop in instances where actors exchange information. This aspect is particularly interesting, as it justifies why typical asymmetric information is greater than the quality of information one usually expects, as earlier works suggest $[17,18,19]$.

This problem may be particularly disadvantageous to the current status of how various economic arenas function. This aspect per se, presents the key deviation in three economic arenas that are exemplified in the next sub-sections.

The use of information asymmetry might guide the understanding of irreversibility of working practices and cultural behaviours in organisations. Thus, we purposely introduce these three examples, since the role of the Internet has had a remarkable impact on how they perform, and how they allow actors to communicate and interact.

\subsection{The newspaper industry}

The use of the Internet in the newspaper industry has caused it to undergo tremendous changes, primarily in the segment of the news distribution services [20]. There are many indicators that show how this industry has taken a downturn in generating economic transactions [5]. One example is when consumers started to inform themselves through the Internet [21]. If the Internet is considered a composite of the digital economy, with new technological advancements, its impact is at the core of our social, technological, and business transitions. It has expanded and pervaded our methods of communication and interaction. This influence on the newspaper industry has also become subject to the distinctiveness and limitations of many technologies. This implies that the newspaper industry follows the current trends of information technology, because it provides innovative ideas to improve communication, but also brings with it a lot of misinformation.

These transitions have also changed the role of the consumer into the role of a user; like an actor that is able to fetch and select types of information without trading any money [5].

Nevertheless, the transition of the newspaper industry did not affect certain existing obstacles. For example, the consistent production of information is not necessarily of a high quality; it is not always transparent and accurate [18]. Hence, it symbolises the presence of information asymmetry. To 
elaborate; a journalist or a correspondent can be considered an information seller. In contrast, the reader can be considered an information buyer. This is a simple explanation of the seller-buyer relationship described by Akerlof, in relation to information exchange.

However, how can this be justified?

To explain, we must look at how information asymmetry becomes evident and is hardly manageable in the newspaper industry:

There are many examples of how journalists or correspondents control the distribution of the news; one way is by releasing information to individuals and changing the original content to align with their own interests. This suggests that their role, which in many cases is the primary source of important information, tends to be uncertain when they become the owners of information. This situation has already proved that most information is manipulated, and its original meaning is diverted and transformed to become information that aligns with the interests of one party $[19,22]$.

Individuals are rarely portrayed as observers of the originality of information. Rather, they are considered observers of obscured information. This is the case, even if the information technology allows people to access news, which undermines the role of the journalists or correspondents; in this case the reader becomes the single owner of news.

\subsection{The health care sector}

The era of the Internet and digital information has introduced many new industries. Databases are increasingly becoming populated with information that is considered to be easily accessible. This has attracted a considerable number of individuals to focus on how digital information can facilitate information exchange in the health care sector. Indeed, the Internet has become a promising method of transmitting information about health care [18]. It has proved to be effective in facilitating interactions between individuals and their information, introducing entirely new forms of communication that are still developing.

Yet, the question remains; is the Internet a safe resource for information exchange? Concerns regarding misinformation and confidentiality of personal information are still apparent. Such analysis, related to health care, has ranked the Internet and digital information as untrustworthy [19].

The impact of the digital economy in health care presents an inter-connected global society where digital information flows freely and without limits across a giant network. It also introduces a revolutionary idea relating to how services are available to individuals - especially in their role as patients, even if their satisfaction or dissatisfaction about services are equally important matters [18].

It is argued that many individuals have turned to the Internet to gain advice about health care problems, supposing that this advice is always quicker then their doctors' information [22].

In many cases, digital information proves useful when health care problems are not too serious. However, the unguarded process of releasing unverified information on the Internet has increased dramatically. This phenomenon may be regarded as a natural development in relation to the current technological trends; however, this analysis does not assess the quality and impact of such information. This has suggested that most of the digital information retrieved from the Internet is in fact, unreliable [22].

Consequently, the digital economy is not likely to resolve fundamental problems in the health care sector, nor is it likely to eliminate the problem of unreliability and misinformation $[19,22]$.

Information asymmetry continues to reveal the weakness of the Internet and the digital information function in real settings. Whether individuals are able to understand what is missing in the digital information provided, or are able to assess whether it is trustworthy or ambiguous information, information asymmetry is still present in the health care sector.

We therefore begin to question how information asymmetry can grow so dramatically, even in the health care sector. The role of the patient searching on the Internet is an example of the information consumer, unexpectedly retrieving asymmetric information. This indicates that the communication process occurs outside the interactions of the health care sector and the patient. This means that digital information is still informal and fragmented, which prevents individuals from successfully managing and controlling the reliability of health related digital information.

\subsection{The stock exchange market}

Stock market movements experience violations of trading, also caused by the operation of misinformation $[17,23]$.

In such violations, market behaviour is totally unpredictable, and many times, it appears as instances of stock price manipulations, which can be highly contagious. In economic transactions, the distribution of misinformation by manipulation (e.g. false reports) is as a result of market behaviour that tends to ignore accurate information, which could potentially lead to more accurate transactions [23]. Such circumstances are detected as the tendency of an individual's motivation to believe in certain forms of information, regardless of changes in the 
environment [23], such as movements in the stock market.

In practice, misinformation becomes pervasive, which leads to different market deviations, purely based on information asymmetry. The following case example symbolises the act of market share failure. Kodak is a company that produces imaging and photographic materials and equipment. In 2001, Kodak's market share dropped to $8 \%$, according to The Wall Street Journal. It appeared to occur as a result of false reporting by Wal-Mart - a public corporation - because of an exclusive deal aiming to sell Polaroid film in lieu of launching a private-label line. Even though a Wal-Mart spokesman accepted that they had not been accurate in their reporting, Kodak shares dropped dramatically.

Similar cases are frequent, even in the current state of world market shares. Recently, the biggest worry regarding a stock exchange downturn was the Dubai problem effect, which, the BBC reported, had impacted on investors and the world financial system. In fact, there is a lot of misinformation surrounding this case, considering that Dubai's problems have also affected their entire country (which their own financial experts had not anticipated).

It is clear that information asymmetry has profound effects on economic transactions. It can be argued that the principle of information asymmetry in today's digital environment is widely recognised as influencing the downturn of market shares. In reality, digital information can quickly become invasive throughout the world, and most of it is released by anonymous users, making the integrity of the process worrying, unpredictable, and inaccurate.

It is suggested therefore that digital information has become enormously dangerous and unpredictable. Information exchange is negatively affecting economic markets forcing them to experience dramatic market declines [17].

The next section presents four patterns of information asymmetry that appear in economic transactions.

\section{Recurrent patterns identified in three examples}

Digital information has developed from the everincreasing digitisation of economic arenas, and has had a great impact on how economic transactions are pursued. This movement has not been felt in the current stages of the digital economy, but rather in the old economy, because of the transformational changes that have impacted on information flows. The digital economy has replaced the old traditions with new ways; for example, managing our mail, our accounts, or how we pay our bills [2].

Following the current trends in ICT, autonomous individuals and organisations are able to create digital information without any restraint. The fundamental nature of digital information becomes more important in information transportation and communication. This has made it possible to gather geographically-distributed information focussed on a single location. All these are factors that have created a more fertile use of technology, viewed as a "general purpose technology" [2, 11]. This technology is considered to have broad power, which can reduce costs of economic transactions that had been excessive in the old economy [2].

However, the unified digital space for economic transactions (that of general purpose technology) is not automatic and easy. Aside from the positive organisational changes, many transformations from the old economy to the digital economy remain uncertain. The new technologies have some conditions that respond to the changes in how digital information is collected and transmitted, often requiring manual interventions regarding interoperability.

This argument relates to the three examples introduced earlier, and is regarded as having important theoretical features. First, the possibilities for interaction and communication are analytically dependent on information asymmetry. Each engagement of digital information in information exchange has a sufficient condition that implies information asymmetry. That is, for the information absorber, digital information has become convenient but not necessarily accurate. Second, all three examples engage cognitive efforts of individuals involved in information exchange. They shape the mental representation of digital information by developing a one-sided view of information. In such cases, this is for the egocentric needs of the information owners. Thus, these sorts of information representations become predecessors of subsequent information. For example, the representation of information, generated from an egocentric view is the main input for presenting feedback information. This can be best explained in relation to how any case, which can be derived from any of the examples presented earlier, function in real settings. Consider two or more actors involved in any information exchange. They develop a representation of a preplanned meaning of information, preventing the absorber from having access to the original meaning, such as in: a) journalism censorship and misinformation; b) health care misinformation; or c) stock exchange misinformation. Third, all of these situations are analytically independent from one another. However, the protocol of information exchange remains the same, in which many overlapping sequences during the process of exchange manifest the inclusion of information asymmetry. This is a pattern that signifies overlapping activities of information exchange in these cases. Finally, this study finds that diverse 
situations, which involve actors in information exchange, emphasise the imbalance between those actors, suggesting that there is always one who usually benefits more than the other. This suggests that such situations suffer from acute information asymmetry. This is one of the crucial problems that has become more visible and intense in the digital economy of digital information.

Such problems may be separately examined in multiple economic arenas, for example with e-health transactions, with e-government on-line documents, or with e-commerce digital transactions. However, there seems to be some recurrent patterns (see below), which increase problems of information asymmetry. In contrast, if all this digital information is to be truly useful and transparent, digital economy must ensure the ability to easily access, analyse, and transport information [11].

The following four key patterns are identified:

1. The original information is influenced.

2. The original meaning of information is manipulated intentionally.

3. The original information is hindered from the information absorber.

4. The information absorber is unaware of the manipulated information.

The matrix in Figure 1 illustrates these four key patterns in relation to economic transactions, originating with the theory of information asymmetry [6].

The four patterns (influenced, intentional, hindered, unawares) are intended to function as forms of communication processes between actors that happen to be engaged in an economic transaction.

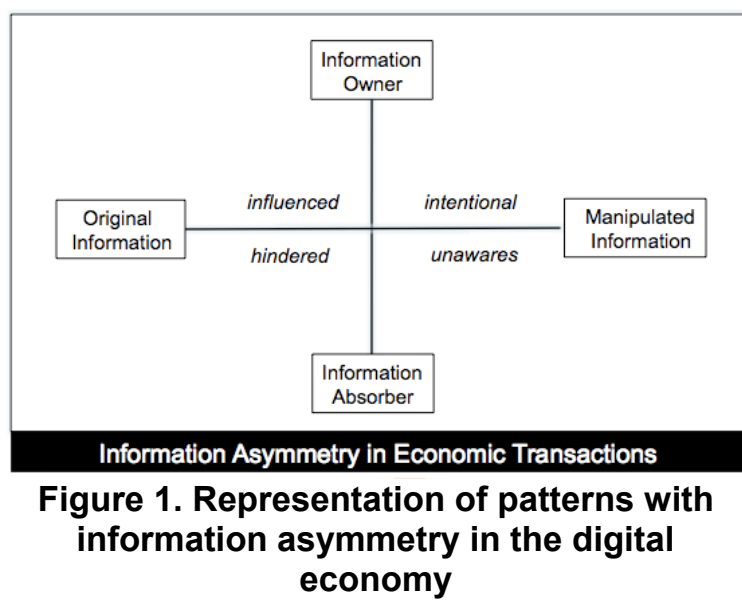

Figure 1 illustrates the patterns that affect the engaged actors. The introduction of new communication forms and the use of new technologies using digital information stem from changes in working practices and cultural behaviours. It is therefore argued that information exchange itself is not new, but its environment has been transformed.

To understand better the role of these patterns in the digital economy, the next section focuses on how the patters occur within the process of information exchange. Initially, we introduce the model of information asymmetry. We relate this model to different information exchange situations, such as those related to the three examples discussed in this paper. Furthermore, the deficiencies of digital information are also introduced.

\section{Information asymmetry model}

The central element of the information asymmetry model is the experience of asymmetry between two actors during an information exchange, i.e., the information owner and the information absorber. This element is critical to understanding the two processes:

\section{a. How information exchange begins and \\ b. How information exchange occurs.}

For the latter process, it is considered to be equivocal, and in this way, the information absorber is unaware of the evolving meanings derived from the information exchange.

This model is presented in Figure 2. Features of each actor in the model are independent. Processes that trigger information flows between these actors are dependent elements. Two actors (information owner and information absorber) function as instruments that mediate information. These actors generate cognitive states that influence the meaning of the information. This figure further illustrates how information is articulated and communicated.

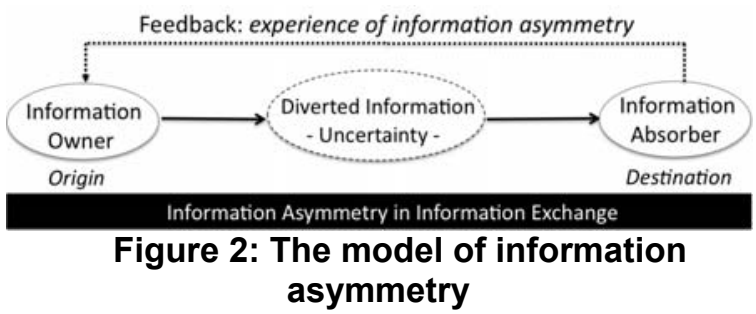

Conceptually, the model draws from two different theories of communication processes. It is addressed through the interactive processes of Shannon's model [24], and advanced by Weiner's inclusion of the feedback process [25]. The feedback process embodies the dependency of information meaning. It involves a variety of cognitive activities, when the actors are depicted as humans.

According to Weiner, the concept of feedback drives interactivity in communication processes. We 
refer to this interactivity as a mutual information exchange process. This is elaborated in Figure 2, which shows that when the process of information exchange occurs, it is also consistent to have a feedback process. The information exchange then evolves from the information owner, by transmitting a message to the information absorber. This signifies harmony in the communication process that allows us to separate it into two discrete actors. Communication between two actors reduces the possibility of having communication linearity. In fact, this has been noticed previously in Shannon's model, in which the role of information absorber is regarded only as an absorbent, without providing feedback.

For this reason, the model in Figure 2 develops the idea of mutual information exchange, implying the insertion of the feedback process. This articulates Weiner's model of the feedback process.

All these illustrated activities have important theoretical features that correspond to the three examples presented earlier. Such information exchange activities motivate accuracy concerns. Actors in these activities usually strive to maintain reasonable and accurate messages. In such interactions, information exchange is uncertain. Hence, actors are more likely to generate information asymmetry and form an information representation of what the absorber would normally experience, which is information asymmetry in an unknowing manner.

Moreover, this model describes the process of feedback as follows: the information meaning relates to the transmitted information from the origin or the source of information - the information owner. It can be received in a different message; typically consisting of diverted information, which is uncertain for the information absorber. This suggests that the actor does not know how or why information asymmetry occurs.

Initially, this whole sequence of information exchange denotes the beginning process of a linear communication. This occurs when the information is released from the owner until it diverts from the original meaning; it features uncertainty during the transmission, which eventually leads to information asymmetry. The communication then continues and involves the information absorber, who engages in the process of information exchange. The information absorber provides feedback information, which already implies information asymmetry. This happens because the actor is unaware of information modifications performed earlier. In Figure 2, this is referred to as diverted information - uncertainty.

These theoretical explanations consist of some significant implications in practice. They serve as an initial diagnosing tool for individuals and organisations that want to understand and enhance the effects of information asymmetry in their activities.

In terms of the information asymmetry theory, this model intends to specify the experiences of uncertainties. It is argued that these experiences prevent individuals and organisations from possessing original meanings of information, which are produced and spread through the digital economy.

\section{Conclusion}

The changing trends and dynamics in the evolving information and communication technologies of the digital economy impact on global economic and societal structures. This paper examines the role of information asymmetry in three economic arenas: a. the newspaper industry; b. the health care sector, and; c. the stock exchange market. The analyses are based on the theory of communication processes, revealing that information asymmetry has become a dominant problem, particularly in relation to how economic transactions operate with digital information. In spite of this, changes in digital economy impact on the use of technologies by creating, storing, and distributing digital information without constraints.

This paper argues that the digital economy represented by digital information has not changed information exchange itself, only its environment. Thus, the objective of the paper tackled the movements of current information exchange trends, which continue to face the problem of information asymmetry. Information asymmetry hinders the different informational needs of individuals and organisations around the world, mainly by limiting their access to relevant information. The problem is expected to increase in the future, together with its repercussions that will also increase.

In terms of digital information, the problem of information asymmetry suggests that sustainability in the digital economy of digital information is still in its early phase of establishing proper communication processes. With respect to the identified information patterns (influenced, intentional, hindered, unawares), at this stage of this study, they suggest the problem is vast. Thus, the identified patters may challenge the sustainability of the current forms of digital information and information exchange, as illustrated in the model of information asymmetry in Figure 2.

Finally, the problem of information asymmetry raises a lot of scepticism, even if comprehensive and relevant information is considered to be available through information systems. This is usually associated with comprehensive and relevant information about products, for which individuals or organisations search: e.g. using Google, e-bay or 
Amazon. Such information is considered to provide examples of how information can be exchanged in new and innovative ways. This indeed shows us that there has been an essential shift in the way digital information is utilised.

Moreover, the digital economy, in combination with aspects, such as information asymmetry, can help to promote sustainability for all human endeavours. However, the increase of misinformation, profoundly affects our economic and social global structures, which has raised a lot of scepticism. Hence, to create value and sustainability for digital information, it remains a profound challenge in need of further investigation.

\section{Acknowledgements}

The author wishes to thank Darek M. Haftor for insightful comments on this paper, and Anita Mirijamdotter for her encouraging comments on earlier versions of this paper.

\section{References}

[1] N-H. Schmidt, K. Erek, M. L. Kolbe, and R. Zarnekow, "Towards a Procedural Model for Sustainable Information Systems Management", Proceedings of the 42nd Hawaii International Conference on Systems Science, Hawaii, 2009, pp. $1-10$.

[2] B. Carlsson, "The Digital Economy: what is new and what is not?", Structural Change and Economic Dynamics, vol. 15, no. 3, pp. 245-264, 2004.

[3] P. M. Senge, G. Carsted, and P.L. Porter, "Innovating our ways to the next industrial decline", MIT Sloan Management Review, vol. 42, no. 2, pp. 24-38, 2001.

[4] M. Ulieru, and J. Verdon, "Organizational Transformation in the Digital Economy", Proceedings of the 7th IEEE International Conference on Industrial Informatics, Cardiff, UK, IEEE, 2009, pp. 17-24.

[5] W. Isaacson, "How to save your newspaper", Time Magazine, vol. 173 , no. 6 , pp. 30-33, 2009.

[6] G. Akerlof, “The Market for 'Lemons': Quality Uncertainty and the Market Mechanism", Quarterly Journal of Economics, vol. 84 , no. 3 , pp. 488-500, 1970.

[7] F. Olivera, S. P. Goodman, and Sh. Swee-Lin Tan, "Contribution Behaviors in Distributed Environments", MIS Quarterly, vol 32, no. 1, 23-42, 2008.

[8] T. Harford, Undercover Economist, Oxford University Press, Oxford, 2005.

[9] D. Tapscott, The Digital Economy: Promise and Peril In The Age of Networked Intelligence (Paperback), McGraw Hill, New York, 1995.
[10] J. van den Berg, "Conceptualising and Analysing Internet Threats using a 4-Dimensional Hypercube", In s.n. (Ed.), Proceedings of the international Conference on Information Society (I-Society 2007), Indiana, USA, 2007, pp. 7-11.

[11] E. Brynjolfsson, and L. Hitt, "Beyond Computation: Information Technology, Organizational Transformation and Business Performance", Journal of Economic Perspectives, vol. 14 , no. 4, pp. 23-48, 2000.

[12] D. Buchanan, L. Fitzgerald, D. Ketley, R. Gollop, J. .L Jones, Sh. Saint Lamont, A. Neath, and E. Whitby, "No Going Back: A Review of the Literature on Sustaining Organ izational Change", International Journal of Management Reviews, vol. 7, no. 3, pp. 189-205, 2005.

[13] J. D. Guertin, "What is Sustainability?", Tunnelling and Underground Space Technology, vol. 11, no. 4, pp. 373-375, 1996.

[14] B. Sheehan, "What is Sustainability?" Control Engineering, vol. 56 , no. 9 , pp. 119-128, 2009.

[15] S. D. Levitt, and S. J. Dubner, S. J. Freakonomics: A Rogue Economist Explores the Hidden Side of Everything, William Morrow, USA, 2005.

[16] Byers, J. W., Mitzenmacher, M., and Zerwas, G. (2010) Information Asymmetries in Pay-Per-Bid Auctions How Swoopo Makes Bank. arXiv:1001.0592v2.

[17] R. A. DeFusco, S. Mishra, and K. Raghunandan, "Changes in the Information Efficiency of Stock Prices: Additional Evidence", The Financial Review, vol. 45, pp.153-165, 2010.

[18] L. Baker, H. T. Wagner, S. Singer, and K. Bundorf, "Use of the Internet and E-mail for Health Care Information" The Journal of American Medical Association, vol. 289, no. 18, pp. 2400-2406, 2003.

[19] P. Starr, "Health Care Reform and the New Economy. Does the new digital economy require a different vision for health reform-its principles as well as its possibility?", Health Affairs, vol. 19, no. 6, pp. 23-32, 2000.

[20] M. Ivancin, and J. Schaffer, "New entrepreneurs: new perspectives on news", Research Report, The Institute for Interactive Journalism, American University School of Communication, 2009, pp. 1-18.

[21] L. G Crovits, "Making old media new again", Wall Street Journal-Eastern Edition, vol. 253, no. 85, p. A13-0, 2009.

[22] P. Jacobson, "Empowering the physician-patient relationship: The effect of the Internet", The Canadian Journal of Library and Information Practice and Research, vol. 2, no. 1, pp. 1-13, 2007.

[23] A. L. Brown, and J. H. Kagel, "Behavior in a simplified stock market: the status quo bias, the disposition effect and the ostrich effect", Annals of Finance, vol. 5, pp.1-14, 2009.

[24] C. E. A. Shannon, "Mathematical Theory of Communication", Bell System Technical Journal, vol. 27, pp. 379423 and 623-656, July and October, 1948

[25] N. Wiener, Cybernetics: or Control and Communication in the Animal and the Machine, John Wiley \& Sons Inc., New York, 1948. 